\title{
Split Hand/Foot Malformation Associated with 7q21.3 Microdeletion: A Case Report
}

\author{
Aswini Sivasankaran ${ }^{\mathrm{a}}$ Ambika Srikanth ${ }^{c}$ Pooja S. Kulshreshtha ${ }^{c}$ \\ Deenadayalu Anuradha $^{b} \quad$ Jayarama S. Kadandale ${ }^{c}$ Chandra R. Samuel ${ }^{a}$
}

${ }^{a}$ Department of Genetics, Dr. ALM PG Institute of Basic Medical Sciences, University of Madras, and ${ }^{b}$ Department of Medical Genetics, Institute of Obstetrics and Gynecology, Government Hospital for Women and Children, Madras Medical College, Chennai, and ${ }^{\mathrm{C} C e n t e r}$ for Human Genetics, Biotech Park, Electronic City Phase I, Bangalore, India

\section{Established Facts}

- A girl diagnosed with split hand/foot malformation (SHFM) type I showed a microdeletion within the sub-band 7q21.3 using FISH with BAC probes and array CGH.

- This case confirms the involvement of the DLX5, DLX6, DSS1, SLC25A13, and DYNC1I1 genes localized to this sub-band and reported to be responsible for the phenotypic features.

\section{Novel Insights}

- The proband also exhibited a larger deletion involving the bands 7q21.11q21.2 confirmed by microarray analysis.

- The significance of genes encoding the class-3 semaphorins SEMA3A, SEMA3D and SEMA3E, and PlexinA2 needs to be explored further.

\section{Key Words}

BAC-FISH · Chromosomal microarray · Developmental delay · Ectrodactyly $\cdot$ High-resolution banding $\cdot$ SHFM1

\section{Abstract \\ Split hand/foot malformation (SHFM) or ectrodactyly is a rare genetic condition affecting limb development. SHFM shows clinical and genetic heterogeneity. It can present as an iso-}

lated form or in combination with additional anomalies affecting the long bones (nonsyndromic form) or other organ systems including the craniofacial, genitourinary and ectodermal structures (syndromic ectrodactyly). This study reports a girl with SHFM who also exhibited developmental delay, mild dysmorphic facial features and sensorineural hearing loss. High-resolution banding analysis indicated an interstitial deletion within the $7 q 21$ band. FISH using locusspecific BAC probes confirmed the microdeletion of $7 q 21.3$.

\section{KARGER 125}

E-Mail karger@karger.com www.karger.com/msy
(C) 2016 S. Karger AG, Basel

1661-8769/16/0066-0287\$39.50/0
Dr. Jayarama S. Kadandale

Center for Human Genetics, Biotech Park

Electronic City Phase I

Bangalore, Karnataka 560100 (India)

E-Mail jayaram@ibab.ac.in 
Chromosomal microarray analysis also revealed a microdeletion of $1.856 \mathrm{Mb}$ in 7q21.3. However, a larger 8.44-Mb deletion involving bands 7q21.11q21.2 was observed, and the breakpoints were refined. The phenotype and the candidate genes underlying the pathogenesis of this disorder are discussed.

(c) 2016 S. Karger AG, Basel

Split hand/foot malformation (SHFM) or ectrodactyly (or lobster claw deformity) is a rare congenital limb deformity. It is characterized by the absence of central digital rays with syndactyly of the remaining digits, deep median cleft, and aplasia or hypoplasia of the phalanges, metacarpals and metatarsals [Scherer et al., 1994b]. The overall prevalence of SHFM is $~ 1 / 8,500-25,000$ newborns accounting for $8-17 \%$ of all limb reduction defects [Gurrieri and Everman, 2013].

The most common mode of inheritance is the autosomal dominant form, with autosomal recessive and $\mathrm{X}$ linked forms occurring more rarely. Segregation distortion characterized by excessive transmission from affected males to sons has also been observed [de Mollerat et al., 2003]. SHFM shows variability in penetrance and expression of the phenotype. Highly variable phenotypes have been observed within affected members of the same family as well as between limbs of a single patient, ranging from mild syndactyly to severe central clefting of the autopods, oligodactyly or monodactyly [Dujif et al., 2003]. Around $40 \%$ of individuals presenting with SHFM have associated non-limb congenital anomalies that include intellectual disability (ID), cleft palate and ectodermal dysplasia. The disorder is genetically heterogeneous involving several loci including 7q21.3, Xq26, 10q24, 3q27, 2q31, and 12q13 [Gurrieri and Everman, 2013; SowińskaSeidler et al., 2014].

SHFM type I (SHFM1) has been known to occur in an isolated form or with additional anomalies affecting the long bones, referred to as the nonsyndromic form or as part of the ectrodactyly-ectodermal dysplasia-cleft syndrome [Crackower et al., 1996]. Both forms were frequently found to be associated with chromosomal rearrangements such as deletions or translocations involving7q21q22. Besides the ectrodactyly-ectodermal dysplasia-cleft syndrome, many other syndromes including SHFM have been described [Gurrieri and Everman, 2013]. This study reports a syndromic form of SHFM1 in a patient associated with a microdeletion of the sub-band 7q21.3, which was confirmed by FISH using BAC clones and array $\mathrm{CGH}$.

\section{Patient and Methods}

Patient

The proband is an 8-month-old, first-born female child to third-degree consanguineous parents (first cousins). It was a normal full-term delivery, and she weighed $2.5 \mathrm{~kg}$ at birth. She was referred to the Department of Genetics, Dr. ALM PGIBMS, at the age of 6 years. The proband exhibited ectrodactyly of the right hand and both feet (fig. 1a, b). Physical examination also revealed facial dysmorphism including a flat occiput, microcephaly, corneal opacity of the left eye and low-set ears. She underwent surgical treatment for patent ductus arteriosus. Follow-up assessment after 2 years revealed developmental delay and bilateral sensorineural hearing loss (fig. 1c, d).

\section{Cytogenetic Analysis}

After having obtained written informed consent from the proband's father, heparinized blood was drawn from the proband and her parents. Elongated metaphase chromosomes were obtained from phytohemagglutinin-stimulated lymphocyte cultures by adding ethidium bromide for $1 \mathrm{~h}$ prior to harvest. Twenty-five metaphases were analyzed from each individual. About 5 well-banded metaphases were documented and karyotyped using Applied Spectral Imaging Systems karyotyping software, BandView version 6.0 (ASI Inc., Carlsbad, Calif., USA). Chromosomal anomalies were designated using standard ISCN nomenclature [ISCN, 2013].

\section{FISH Analysis}

FISH was performed on metaphase chromosome spreads prepared from lymphoblastoid cells using probes of DNA isolated from 5 BAC clones spanning the sub-band 7q21.3 and localized to the $7 \mathrm{q} 21.2 \mathrm{q} 22.1$ region following manufacturer's protocol. These clones were selected from the human DNA RP11 library in the UCSC genome browser and provided by BACPAC Resources (http://bacpac.chori.org/home.htm). The BAC probes were each $\sim 180-200 \mathrm{~kb}$ in size and included RP11-1080O8, RP11-737I16 and RP11-991E7 localized to 7q21.3, RP11-998E13 (7q21.2) and RP11-794O22 (7q22.1). DNA extracted from these BAC clones were labeled with digoxigenin 11-dUTP by nick translation according to standard protocols. FISH probes were hybridized to the slides and detected using anti-DIG antibody tagged with rhodamine. The commercially available probe specific for the centromeric region of chromosome 7 was also used for reference.

\section{Whole-Genome Array-CGH Analysis}

Genomic DNA was isolated from lymphocytes using the phenol-chloroform-isoamyl alcohol method. Whole-genome arrayCGH analysis was performed using Affymetrix CytoScan ${ }^{\circledR} 750 \mathrm{~K}$ microarray (Affymetrix Inc., Santa Clara, Calif., USA) consisting of 750,000 oligonucleotide probes across the genome (including $550 \mathrm{~K}$ unique non-polymorphic probes and 200K SNP probes) following manufacturer's instructions at Innovative Life Discoveries Pvt. Ltd., Gurgaon, Harayana, India. Approximately 250 ng of DNA was digested with Nsp1 and then ligated by Nsp1 adapter. Titanium Taq amplified PCR products were purified using AMP pure beads. Purified DNA was fragmented to the product size of 25-125 bp, biotin labeled, hybridized on CytoScan 750K array, and then scanned for cell file generation. Detailed analysis was done using Affymetrix Chromosome Analysis Suite (ChAS) software ver. 1.1. Localization of gains and losses in copy number was done using the UCSC Genome Browser Assembly. 

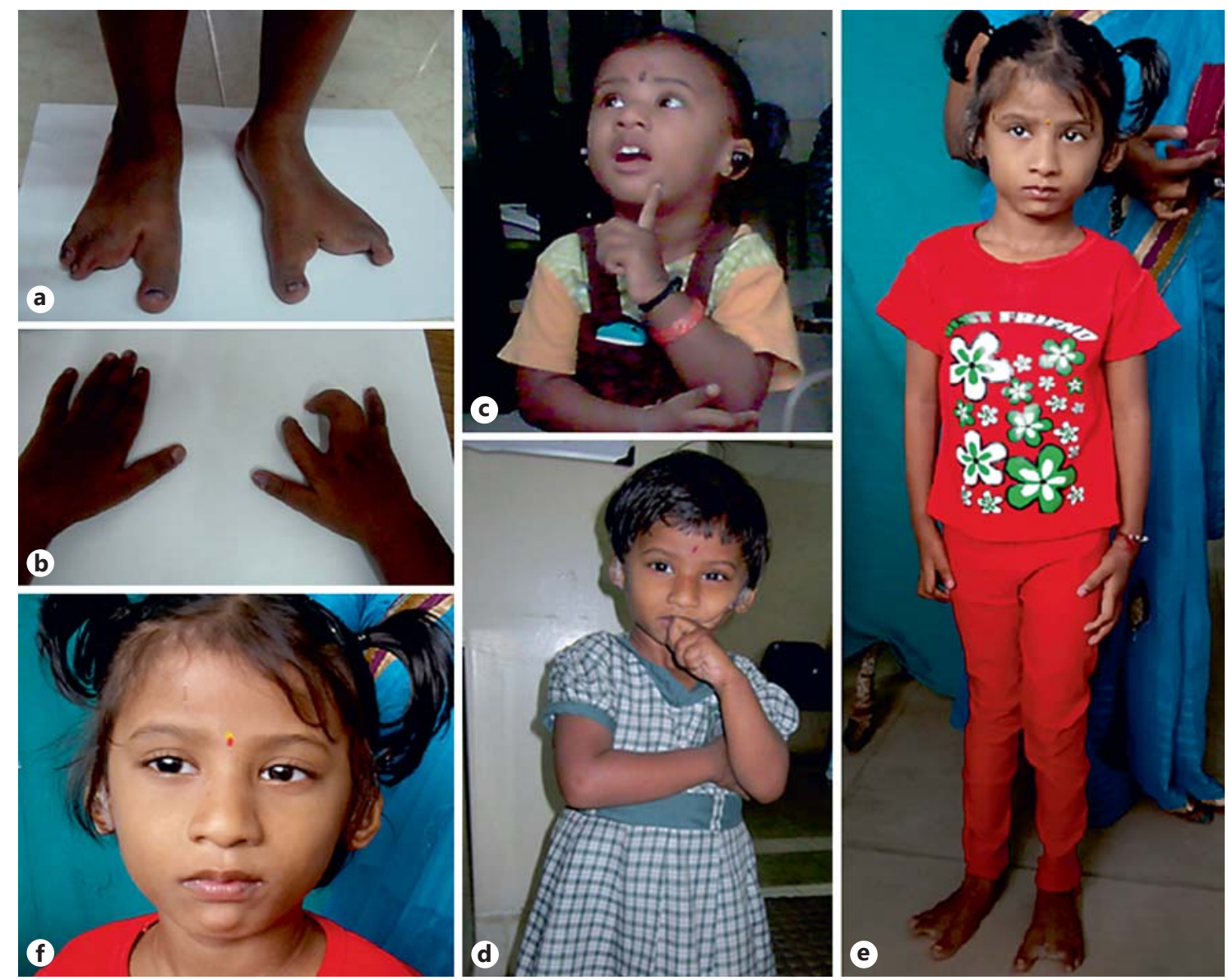

f
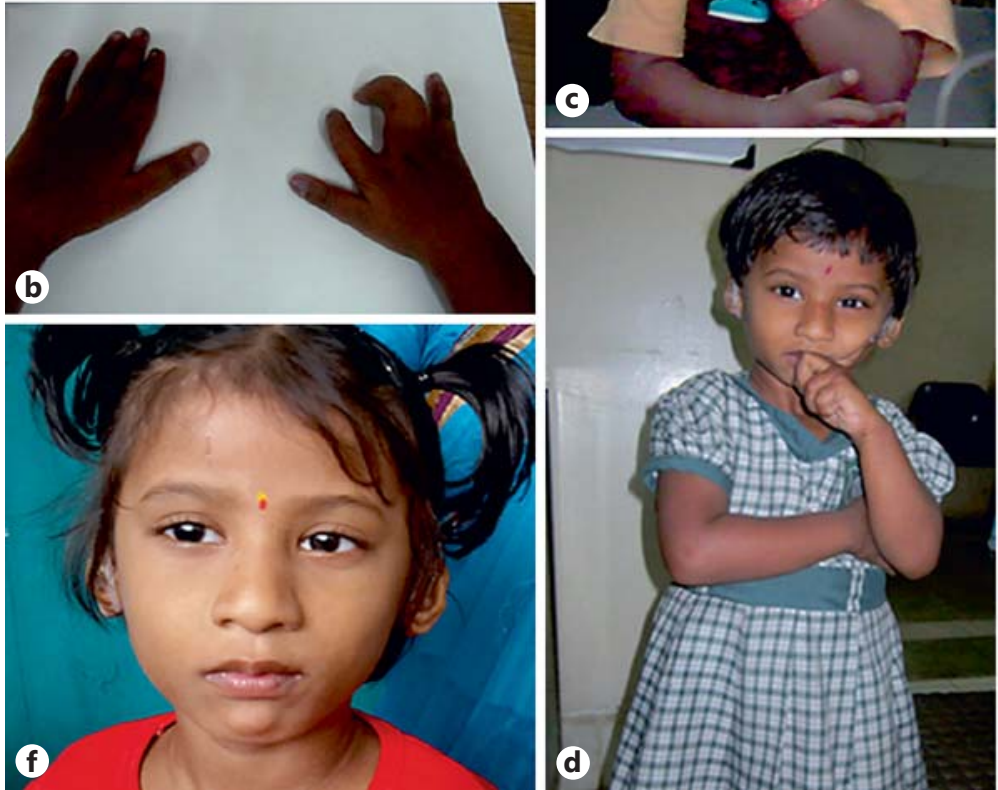

e

Fig. 1. Both feet (a) and the right hand (b) of the proband show ectrodactyly. Photographs of the proband at about $2 \frac{1}{2}$ (c), $4 \frac{1}{2}$ (d) and 6 years of age (e). Photograph of the girl's face at her present age of 6 years (f).

\section{Results}

Chromosomal analysis at 650-band resolution showed an interstitial deletion within the band 7q21 of the proband (fig. 2a). Both parents showed a normal karyotype (fig. 2b, c). FISH analysis using the BAC clone RP11-737I16 $(95,059,137-95,262,009)$ together with a probe for the centromeric region of chromosome 7 (control) disclosed a microdeletion within the sub-band 7q21.3 (fig. 3e). Two signals were viewed for the remaining clones, RP11-1080O8 and RP11-991E7 mapped to 7q21.3, RP11-998E13 to 7q21.2 and RP11-794O22 to 7q22.1 (fig. 3a-d). Chromosomal microarray (CMA) analysis using Affymetrix CytoScan $750 \mathrm{~K}$ microarray chip further confirmed and revealed a microdeletion of $1.856 \mathrm{Mb}$ within 7q21.3 (arr[hg19] $7 q 21.3(94,883,839-96,739,875) \times 1)$ besides a larger deletion encompassing $8.44 \mathrm{Mb}$ at 7q21.11q21.2 (arr[hg19] 7q21.11q21.2(83,236,518-91,680,906)×1) (fig. 4a). Based on these results, the karyotype was rewritten as $46, \mathrm{XX}$, del(7)(q21.11q21.2).ish del(7)(q21.3q21.3)(RP11-737I16-). The CMA analysis also revealed a $35-\mathrm{Mb}$ long region of homozygosity on chromosome 18 ( $\operatorname{arr}[\mathrm{hg} 19] 18 \mathrm{q} 12$. 1q22.1 $(29,156,998-64,771,932) \times 2 \mathrm{hmz}$ ) (fig. 4b).

\section{Discussion}

Chromosomal rearrangements of the 7q21.3q22.1 region are associated with SHFM1 and occur mostly as a sporadic event. Besides limb anomalies, this region is associated with a wide spectrum of phenotypes, including growth impairment, microcephaly, craniofacial manifestations, hearing loss, and ID that differ in affected individuals (table 1). This critical region has also been implicated in ectrodactyly-ectodermal dysplasia-cleft lip/palate syndrome. Although the proband had hearing loss 


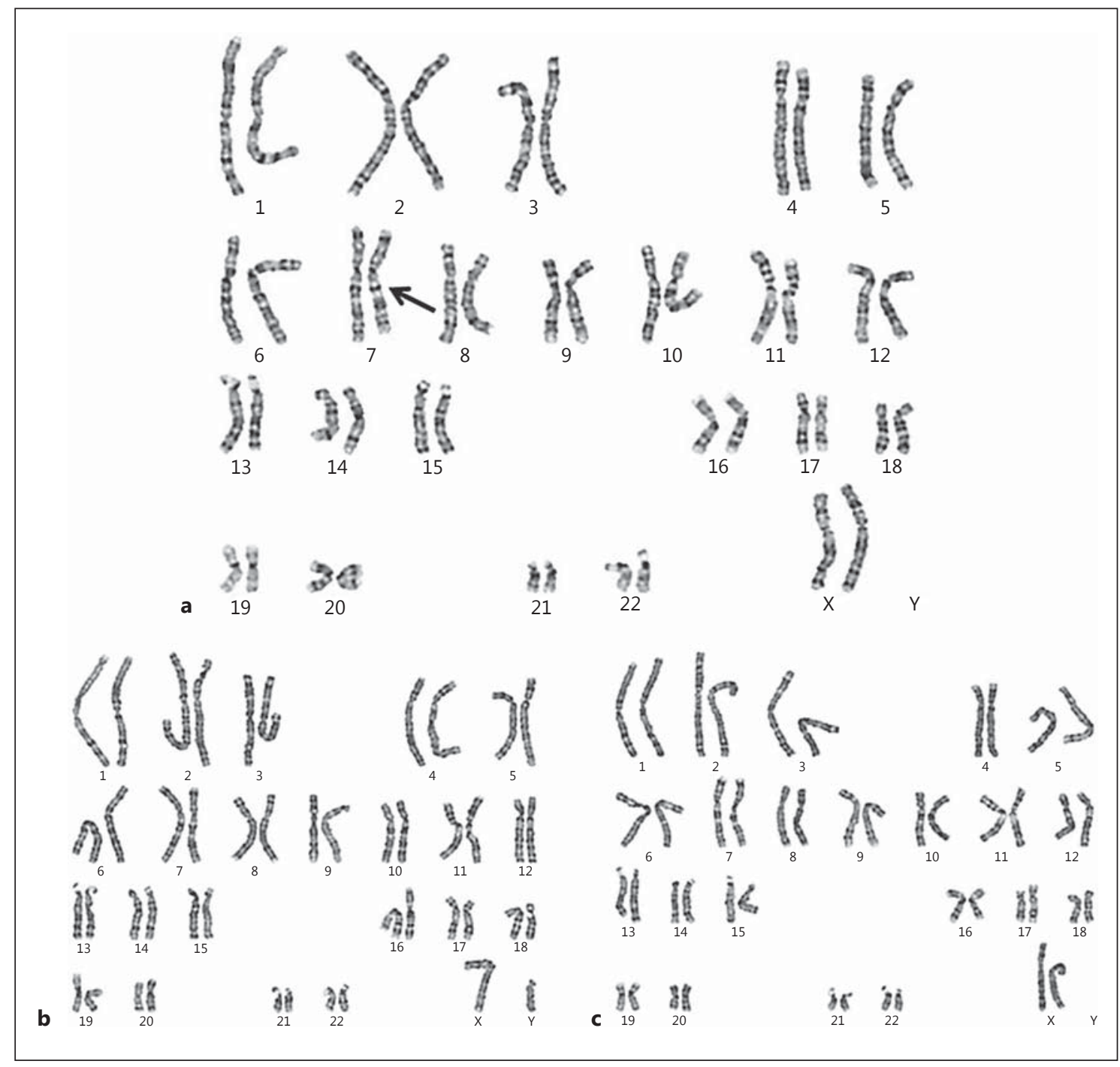

Fig. 2. GTG-banded karyogram showing an interstitial deletion within the band 7q21 (arrow) in the proband (a) and normal patterns in her parents $(\mathbf{b}, \mathbf{c})$.

with ectrodactyly, she did not exhibit a cleft palate. This is indicative of variable expression and is consistent with existing literature.

It is interesting to note that ID is more often associated with deletions than translocations. Initially, 3 genes present in the 7q21.3q22.1 region, DLX5, DLX6 and DSS1, were thought to play a role in limb development. The DSS1 gene (deleted in SHFM1) was found to be expressed in regions of rapid cell growth (limb bud, branchial arches, genital bud, and skin) and excluded from regions of cell differentiation [Crackower et al., 1996]. Though the DSS1 gene is involved in many biological and cellular processes including development, differentiation, cellu- lar proliferation, neoplastic transformation, and ubiquitin dependent proteolysis, an involvement of this gene in the manifestation of this phenotype was unlikely as Dss 1 expression was normal in the combined homozygous Dlx $5 /^{-/-}$mice exhibiting a SHFM1 phenotype [Merlo et al., 2002; Dujif et al., 2003].

Molecular characterization of the genomic rearrangements involving the $7 \mathrm{q} 21.3$ sub-band led to the determination of a probable role of DLX5 and DLX6 genes, the Drosophila distal-less-related homeobox genes, in limb development. Both were expressed in the apical ectodermal ridge of the developing limbs, and a disruption in this ridge signaling was suggested to be a major cause of 

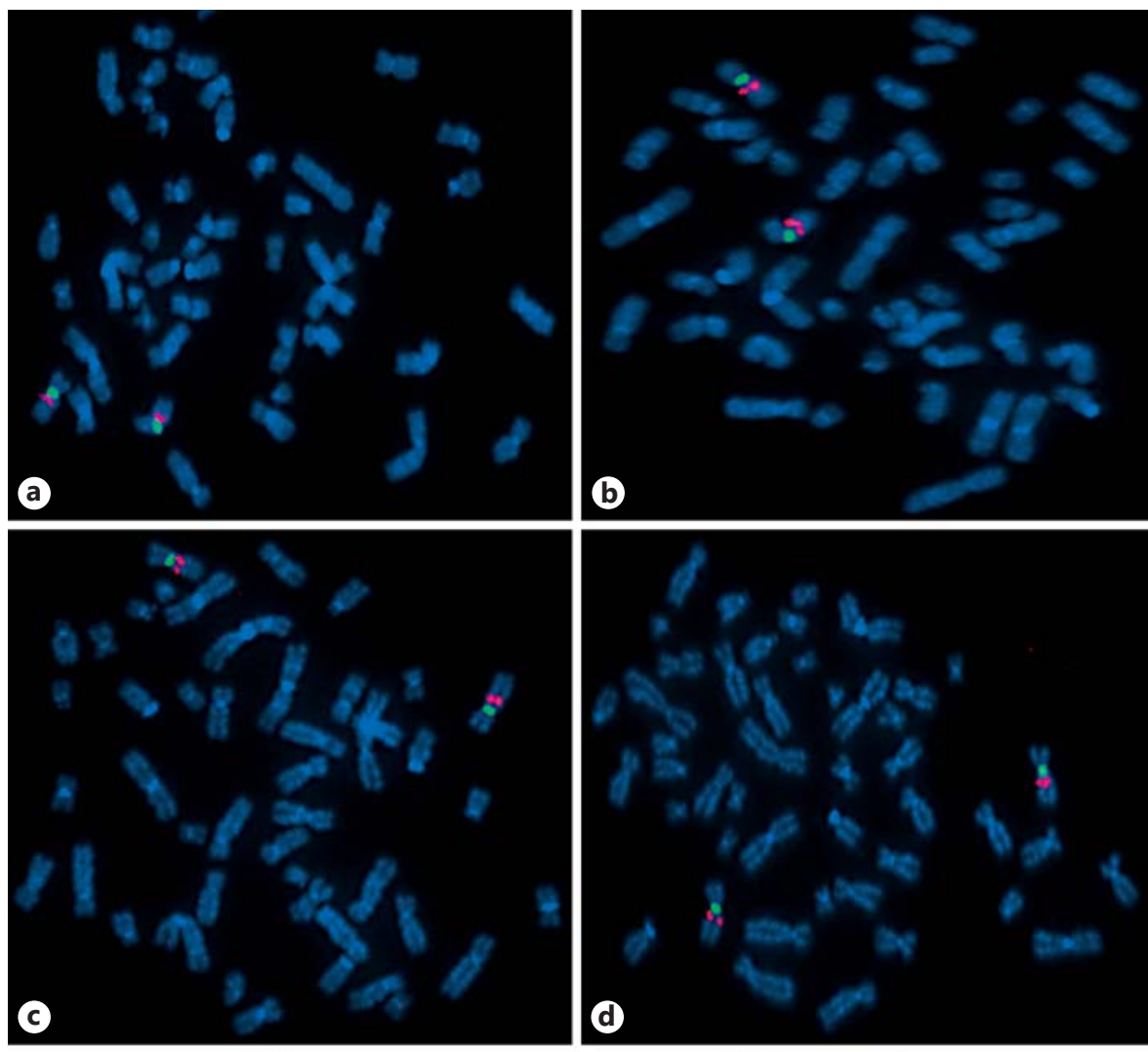

Fig. 3. FISH analysis with the BAC clone RP11-737I16 (7q21.3) (red) and control probe for chromosome 7 centromeric region (green) confirms the microdeletion (arrow) (e). The other BAC clones (red) RP11-1080O8 and RP11-991E7 (7q21.3), RP11-998E13 (7q21.2) and RP11-794O22 (7q22.1) showed a normal hybridization pattern $(\mathbf{a}-\mathbf{d})$.

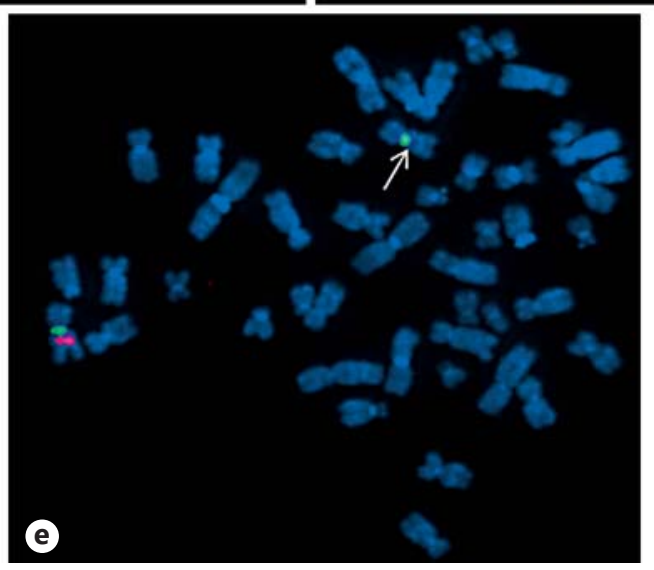

SHFM [Dujif et al., 2003]. Knockout studies in mice showed that an SHFM-like phenotype was observed only when both $D l x 5$ and $D l x 6$ were deleted [Crackower et al., 1996]. This indicated that the 2 genes participate co-operatively in a common developmental pathway [Kowenhoven et al., 2010]. Moreover, they were also expressed in the craniofacial prominence, the otic vesicle and in the brain, which correlates well with the sensorineural hearing loss and ID that are each present in about $30 \%$ of the SHFM1 patients [Tayebi et al., 2014]. These features were also observed in the proband. However, recently mutations in only the DLX5 gene have been reported in affected individuals. Shamseldin et al. [2012] reported a novel intragenic missense mutation in a highly conserved residue of the homeobox domain of DLX5. Likewise, a novel heterozygous mutation, c.558G $>\mathrm{T}$ (p.Gln186His) in DLX5 was reported in both mother and son affected with SHFM1 [Wang et al., 2014].

A SHFM1 phenotype was recently reported in 2 affected members of the same family carrying a 106-kb de- 
Fig. 4. Array CGH. A 1.856-Mb microdeletion of $7 q 21.3$ and an $8.44-\mathrm{Mb}$ deletion at $7 \mathrm{q} 21.11 \mathrm{q} 21.2$ (a). A 35-Mb long region of homozygosity at 18q12.1q22.1 (b).
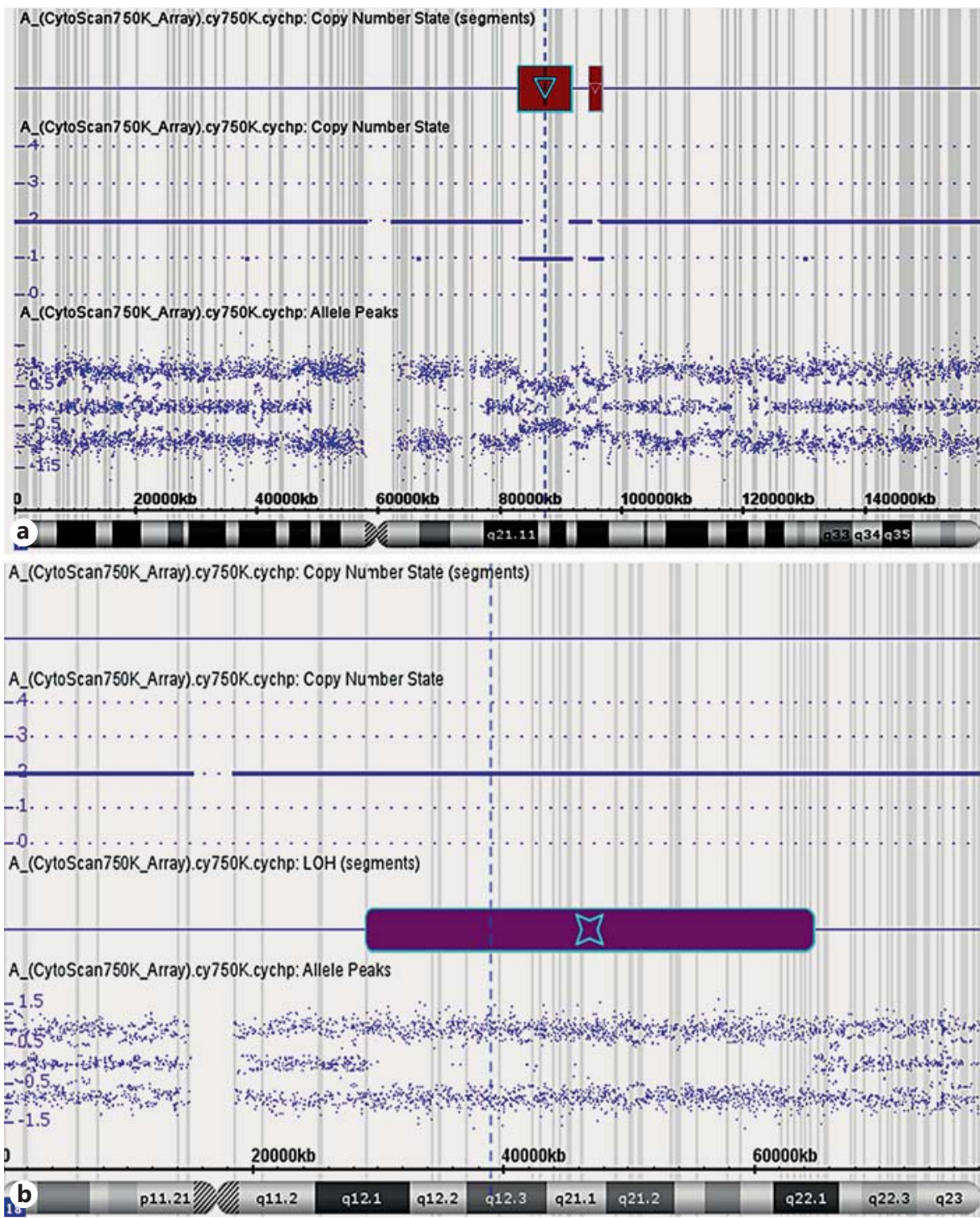

letion that did not disrupt the $D L X 5 / 6$ pair. It is the smallest deletion identified so far within the SHFM1 region. The deletion was found to encompass exons 11-18 of the SLC25A13 (solute carrier family 25 member 13 ) gene and exons 14-17 of the DYNC1I1 (dynein cytoplasmic 1 intermediate chain 1) gene [Lango Allen et al., 2014]. Multitissue enhancers have been reported earlier to reside in exons 15 and 17 of the DYNC1I1 gene and intron 14 of the SLC25A13 gene with the latter playing a role in the otic vesicle [Birnbaum et al., 2012]. The phenotype can thus be attributed to true haploinsufficiency of $D L X 5 / 6$ genes or functional haploinsufficiency resulting from the disruption of cis-acting regulatory elements through physical separation from their target $D L X 5 / 6$ genes [van
Silfhout et al., 2009; Birnbaum et al., 2012; Lango Allen et al., 2014]. Tayebi et al. [2014] reported overlapping deletions of the exonic enhancers 15 and 17 of DYNC1I1 in affected individuals from 3 families with an autosomal dominant nonsyndromic, bilateral SHFM, and deletion of the last 3 exons of the SLC25A13 gene in addition in the fourth family with hearing loss. CMA analysis showed a $1.856-\mathrm{Mb}$ microdeletion in $7 \mathrm{q} 21.3$ which encompassed all the 5 genes, DLX5, DLX6, DSS1, SLC25A13, and DYNC1I1, in the proband. The development of molecular diagnostic testing, including array CGH, greatly contributes to the determination of the genetic variation underlying this clinically heterogeneous congenital defect and consequently to genetic counseling, and also to 
Table 1. Phenotype associated with chromosome rearrangements involving 7q21

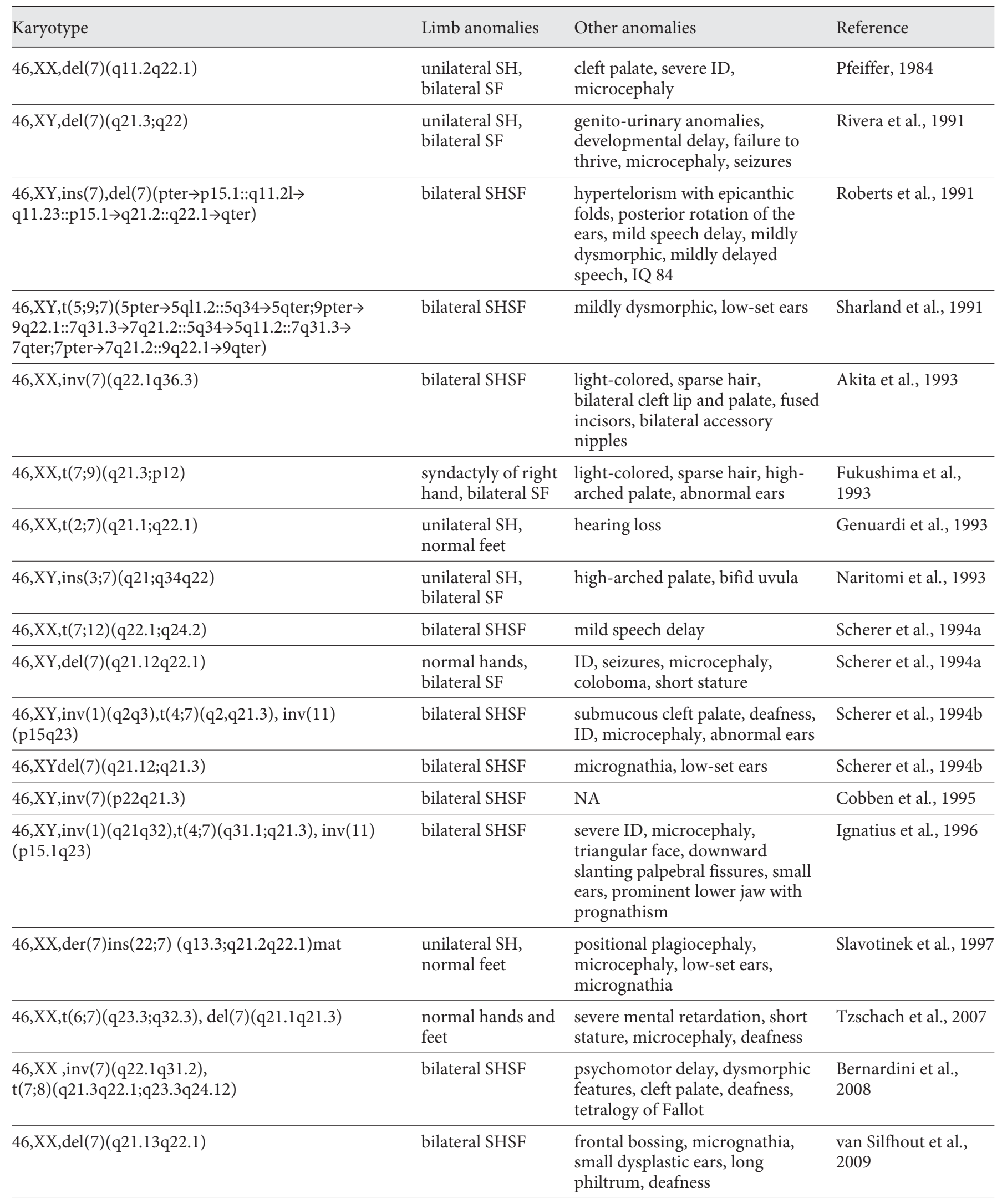


Table 1 (continued)

\begin{tabular}{|c|c|c|c|}
\hline Karyotype & Limb anomalies & Other anomalies & Reference \\
\hline $46, \mathrm{XX}, \operatorname{del}(7)(\mathrm{q} 21.11 \mathrm{q} 21.3)$ & $\begin{array}{l}\text { syndactyly of right } \\
\text { foot }\end{array}$ & $\begin{array}{l}\text { low-set ears, upslanting and } \\
\text { short palpebral fissures, small } \\
\text { mouth and retrognathia, } \\
\text { sensorineural hearing loss }\end{array}$ & $\begin{array}{l}\text { van Silfhout et al., } \\
2009\end{array}$ \\
\hline 46,XY,inv(7)(p22q21.3) & bilateral SHSF & NA & $\begin{array}{l}\text { van Silfhout et al., } \\
2009\end{array}$ \\
\hline $46, X Y, t(7 ; 13)(q 21 ; q 32.1)$ & SHFM1 & NA & Obenauf et al., 2010 \\
\hline $\mathrm{t}(2 ; 7)(\mathrm{p} 25.1 ; \mathrm{q} 21.3)$ & $\begin{array}{l}\text { unilateral SHSF, } \\
\text { syndactyly of the } \\
\text { left foot }\end{array}$ & NA & $\begin{array}{l}\text { Lango Allen et al., } \\
2014\end{array}$ \\
\hline
\end{tabular}

$\mathrm{NA}=$ Not available; $\mathrm{SF}=$ split foot; $\mathrm{SH}=$ split hand; SHSF = split hand, split foot.

the discovery of novel genes in cases of uncertain origin [Sowińska-Seidler et al., 2014].

The proband was also found to exhibit a larger deletion involving the bands $7 \mathrm{q} 21.11 \mathrm{q} 21.2$, which localizes genes encoding the class-3 semaphorins SEMA3A, SEMA3D and SEMA3E. These secreted proteins have been known to be involved in neuronal functions such as axon attraction and repulsion, apoptosis, cell migration, and growth cone collapse. Sema3s require binding to transmembrane receptors that comprise of heteromeric complexes of neuropilins, plexins and cell adhesion molecules [Sharma et al., 2012]. Plexins have established roles in regulating Rho-family GTPases. Some of the cell adhesion molecules and genes regulating Rho signaling have been implicated in various forms of ID [Govek et al., 2005]. It is probable that haploinsufficiency of the semaphorin genes may be responsible for the reduced cognitive function observed in the proband. SEMA3E has been proved to play an important role in ensuring the specificity of synapse formation [Ding et al., 2011]. Semaphorin signaling also plays a critical role in neural crest-mediated heart development through its interaction with PlexinA2 [Brown et al., 2001] and may explain the cardiac defect seen in our proband. Congenital heart defects are reported in 10\% of SHFM1 patients [Elliot and Evans, 2008].

Additionally, CMA analysis revealed a $35-\mathrm{Mb}$ region of homozygosity at 18q12.1q22.1 in the proband which could be attributed to the consanguinity of her parents. This region also contains the genes PIK3C3, RIT2 and SYT4 that have been associated with individuals affected with ID [Cody et al., 2007; Buysse et al., 2008; Vulto-van
Silfhout et al., 2013]. The genes RNF165 and EPG5 have been related to neuronal damage with the latter being linked to the multisystem disorder Vici syndrome [Kelly et al., 2013; Zhao et al., 2013]. The involvement of SMAD2 and ST8SIA5 proteins in neural induction and differentiation also makes them ideal candidates for the phenotype of the proband [Chang and Harland, 2007; Kwak et al., 2011]. Further, the LOXHDI gene present in the same locus is associated with nonsyndromic hearing loss [Dror and Avraham, 2010]. The involvement of these genes in the phenotype of the proband is uncertain and requires further analysis including parental testing to rule out uniparental disomy or identity by descent.

In conclusion, application of CMA analysis supported the precise delineation of the $7 \mathrm{q}$ breakpoint in our patient. This report on molecular characterization of the chromosomal abnormality in the SHFM patient will not only confirm the role of known candidate genes, but also will help in the identification of novel genes and, in turn, the pathogenetic mechanisms underlying the clinical heterogeneity associated with this disorder. This will also have important implications for risk assessment, management and genetic counseling.

\section{Acknowledgments}

Financial support by UGC-BSR as a junior research fellowship to A. Sivasankaran is gratefully acknowledged. C.R.S. and A. Sivasankaran thank UGC-SAP, DST and the University of Madras for the infrastructural facilities. 


\section{Statement of Ethics}

This study was approved by the Institutional Ethics Committee. Written informed consent from the proband's father to participate in this study, including the publication of images, was obtained.

\section{Disclosure Statement}

The authors have no conflicts of interest to declare.

\section{References}

Akita S, Mukae N, Abe K, Harada N, Fujii T, Niikawa N: EC syndrome in a girl with paracentric inversion (7)(q22.1;q36.3). Clin Dysmorphol 2:62-67 (1993).

- Bernardini L, Palka C, Ceccarini C, Capalbo A, Bottillo I, et al: Complex rearrangement of chromosomes 7q21.13-q22.1 confirms the ectrodactyly-deafness locus and suggests new candidate genes. Am J Med Genet A 146A:238-244 (2008).

- Birnbaum RY, Clowney EJ, Agamy O, Kim MJ, Zhao J, et al: Coding exons function as tissuespecific enhancers of nearby genes. Genome Res 22:1059-1068 (2012).

- Brown CB, Feiner L, Lu MM, Li J, Ma X, et al: PlexinA2 and semaphorin signaling during cardiac neural crest development. Development 128:3071-3080 (2001).

- Buysse K, Menten B, Oostra A, Tavernier S, Mortier GR, Speleman F: Delineation of a critical region on chromosome 18 for the $\operatorname{del}(18)$ (q12.2q21.1) syndrome. Am J Med Genet A 146A:1330-1334 (2008).

-Chang C, Harland RM: Neural induction requires continued suppression of both Smad1 and Smad2 signals during gastrulation. Development 134:3861-3872 (2007).

-Cobben JM, Verheij JB, Eisma WH, Robinson $\mathrm{PH}$, Zwierstra RP, et al: Bilateral split hand/ foot malformation and inv(7)(p22q21.3). J Med Genet 32:375-378 (1995)

-Cody JD, Sebold C, Malik A, Heard P, Carter E, et al: Recurrent interstitial deletions of proximal 18q: a new syndrome involving expressive speech delay. Am J Med Genet A 143A:11811190 (2007).

-Crackower MA, Scherer SW, Rommens JM, Hui CC, Poorkaj P, et al: Characterization of the split hand/split foot malformation locus SHFM1 at 7q21.3-q22.1 and analysis of a candidate gene for its expression during limb development. Hum Mol Genet 5:571-579 (1996).

de Mollerat XJ, Gurrieri F, Morgan CT, Sangiorgi E, Everman DB, et al: A genomic rearrangement resulting in a tandem duplication is associated with split hand-split foot malformation 3 (SHFM3) at 10q24. Hum Mol Genet 12: 1959-1971 (2003).

Ding JB, Oh WJ, Sabatini BL, Gu C: Semaphorin 3E-Plexin-D1 signaling controls pathwayspecific synapse formation in the striatum. Nat Neurosci 15:215-223 (2011).
Dror AA, Avraham KB: Hearing impairment: a panoply of genes and functions. Neuron 68 : 293-308 (2010).

-Duijf PHG, van Bokhoven H, Brunner HG: Pathogenesis of split-hand/split-foot malformation. Hum Mol Genet 12 Spec No 1:R51R60 (2003).

Elliot AM, Evans JA: The association of split hand foot malformation (SHFM) and congenital heart defects. Birth Defects Res Part A Clin Mol Teratol 82:425-434 (2008).

Fukushima Y, Ohashi H, Hasegawa T: The breakpoints of the EEC syndrome (ectrodactyly ectodermal dysplasia and cleft lip/cleft palate) confirmed to 7qll.21 and 9pl2 by fluorescence in situ hybridization. Clin Genet 44:50 (1993).

Genuardi M, Pomponi MG, Sammito V, Bdlussi A, Zollino M, Neri G: Split hand/foot anomaly in a family segregating a balanced translocation with breakpoint on 7q22.1. Am J Med Genet 47:823-831 (1993).

Govek E, Newey SE, Van Aelst L: The role of the Rho GTPases in neuronal development. Genes Dev 19:1-49 (2005).

Gurrieri F, Everman DB: Clinical, genetic, and molecular aspects of split-hand/foot malformation: an update. Am J Med Genet A 161A:2860-2872 (2013).

Ignatius J, Knuutila S, Scherer SW, Trask B, Kere J: Split hand/split foot malformation, deafness, and mental retardation with a complex cytogenetic rearrangement involving 7q21.3. J Med Genet 33:507-510 (1996).

ISCN 2013: An International System for Human Cytogenetic Nomenclature, Shaffer LG, McGowan-Jordan J, Schmid M (eds) (Karger, Basel 2013).

Kelly CE, Thymiakou E, Dixon JE, Tanaka S, Godwin J, Episkopou V: Rnf165/Ark2C enhances BMP-Smad signaling to mediate motor axon extension. PLoS Biol 11:e1001538 (2013).

Kouwenhoven EN, van Heeringen SJ, Tena JJ, Oti M, Dutilh BE, et al: Genome-wide profiling of p63 DNA-binding sites identifies an element that regulates gene expression during limb development in the 7q21 SHFM1 locus. PLoS Genet 6:e1001065 (2010).

Kwak DH, Jin JW, Ryu JS, Ko K, Lee SD, et al: Regulatory roles of ganglioside GQ1b in neuronal cell differentiation of mouse embryonic stem cells. BMB Rep 44:799-804 (2011).
Lango Allen H, Caswell R, Xie W, Xu X, Wragg C, et al: Next generation sequencing of chromosomal rearrangements in patients with splithand/split-foot malformation provides evidence for DYNC1I1 exonic enhancers of DLX5/6 expression in humans. J Med Genet 51:264-267 (2014)

Merlo GR, Paleari L, Mantero S, Genova F, Beverdam A, et al: Mouse model of split hand/foot malformation type I. Genesis 33:97-101 (2002).

Naritomi K, Izumikawa Y, Tohma T, Hirayana K: Inverted insertion of chromosome $7 \mathrm{q}$ and $\mathrm{ec}$ trodactyly. Am J Med Genet 46:492-493 (1993).

- Obenauf AC, Schwarzbraun T, Auer M, Hoffmann EM, Waldispuehl-Geigl J, et al: Mapping of balanced chromosome translocation breakpoints to the basepair level from microdissected chromosomes. J Cell Mol Med 14: 2078-2084 (2010).

Pfeiffer RA: Interstitial deletion of a chromosome 7(q11.2q22.1) in a child with split hand/split foot malformation. Ann Genet 27:45-48 (1984).

Rivera H, Sanchez-Corona J, Burgos-Fuentas VR, Melendez-Ruiz MJ: Deletion of 7q22 and ectrodactyly. Genet Couns 2:27-31 (1991).

Roberts SH, Hughes HE, Davies SJ, Meredith AL: Bilateral split hand and split foot malformation in a boy with a de novo interstitial deletion of $7 \mathrm{q} 21.3$. J Med Genet 28:479-481 (1991).

-Scherer SW, Poorkaj P, Allen T, Kim J, Geshuri D, et al: Fine mapping of the autosomal dominant split hand/split foot locus on chromosome 7, band q21.3-q22.1. Am J Hum Genet 55:12-20 (1994a).

Scherer SW, Poorkaj P, Massa H, Soder S, Allen T, et al: Physical mapping of the split hand/ split foot locus on chromosome 7 and implication in syndromic ectrodactyly. Hum Mol Genet 3:1345-1354 (1994b).

Shamseldin HE, Faden MA, Alashram W, Alkuraya FS: Identification of a novel DLX5 mutation in a family with autosomal recessive split hand and foot malformation. J Med Genet 49:16-20 (2012)

- Sharland M, Patton MA, Hill L: Ectrodactyly of hands and feet in a child with a complex translocation including7q21.2. Am J Med Genet 39:413-414 (1991). 
Sharma A, Verhaagen J, Harvey AR: Receptor complexes for each of the Class 3 Semaphorins. Front Cell Neurosci 6:28 (2012).

-Slavotinek A, Maher E, Gregory P, Rowlandson P, Huson SM: The phenotypic effects of chromosome rearrangement involving bands 7q21.3 and 22q13.3. J Med Genet 34:857-861 (1997).

-Sowińska-Seidler A, Socha M, Jamsheer A: Splithand/foot malformation - molecular cause and implications in genetic counseling. J Appl Genet 55:105-115 (2014).
Tayebi N, Jamsheer A, Flöttmann R, SowinskaSeidler A, Doelken SC, et al: Deletions of exons with regulatory activity at the DYNC1I1 locus are associated with split-hand/split-foot malformation: array CGH screening of 134 unrelated families. Orphanet J Rare Dis 9:108 (2014).

Tzschach A, Menzel C, Erdogan F, Schubert M, Hoeltzenbein $M$, et al: Characterization of a $16 \mathrm{Mb}$ interstitial chromosome 7q21 deletion by tiling path array CGH. Am J Med Genet A 143:333-337 (2007).

van Silfhout AT, van den Akker PC, Dijkhuizen T, Verheij JBGM, Olderode-Berends MJW, et al: Split hand/foot malformation due to chromosome $7 \mathrm{q}$ aberrations (SHFM1): additional support for functional haploinsufficiency as the causative mechanism. Eur J Hum Genet 17:1432-1438 (2009).
Vulto-van Silfhout AT, Hehir-Kwa JY, van Bon BW, Schuurs-Hoeijmakers JH, Meader S, et al: Clinical significance of de novo and inherited copy-number variation. Hum Mutat 34: 1679-1687 (2013).

Wang X, Xin Q, Li L, Li J, Zhang C, et al: Exome sequencing reveals a heterozygous $D L X 5 \mathrm{mu}$ tation in a Chinese family with autosomaldominant split-hand/foot malformation. Eur J Hum Genet 22:1105-1110 (2014).

Zhao YG, Zhao H, Sun H, Zhang H: Role of Epg5 in selective neurodegeneration and Vici syndrome. Autophagy 9:1258-1262 (2013). 